\title{
ASSESSMENT OF THE WIND FARM IMPACT ON POWER SYSTEM STABILITY WHILE REDUCING OF TOTAL INERTIA
}

\author{
Razzhivin I.A.*, Ruban N.Yu., Rudnik V.E. \\ National Research Tomsk State University, Tomsk, Russia, lionrash@tpu.ru
}

\begin{abstract}
With the development of wind power in the world, the issues of joint operation of wind power plants in power systems become relevant. Modern variable speed wind turbines with are connected to the network through power voltage converters, which, with their significant integration into the power systems, negatively affects the transient stability of such systems, the operation of emergency control devices, etc. The problem is caused by the effect of "decoupling" of the wind turbine generators from the power systems, since the connection of the mechanical moment of the wind turbine with the power system is lost, its frequency characteristics also change, the overall inertia of the system decreases, and as a consequence, these phenomena can lead to rapid fluctuations in frequency and voltage in normal modes, and also an avalanche of frequency and voltage in case of accidents. In addition, a decrease in the total inertia can contribute to the failure of out-of-step protection systems for eliminating the out-of-step mode, due to an increase in the slip frequency. In the article, experimental studies of the implementation of wind power plants in power system to assess the impact of their work on the rate of the transients.
\end{abstract}

Keywords: wind turbine, inertia, out-of-step mode

\section{Introduction}

The world is seeing the dynamics of the penetration of new renewable energy sources (RES), mainly wind power plants (WPP). According to the reports [1-2], the total generated capacity of WPP in the world has more than tripled over the past 10 years and amounts to $651 \mathrm{GW}$ (5.9\% of world electricity production). With an increase in the share of RES, their influence on electric power systems (EPS) increases, which creates certain challenges in modes control, maintaining the balance of power, stability and reliability of EPS. Among other things, the problem of reducing the total inertia in EPS is becoming urgent. A decrease in the total inertia is due to the presence of a power voltage converter in the structures of modern renewable energy sources (wind turbines of the 3-rd and 4-th types, solar power plants), there are no rotating mechanisms in solar power plants, and the generators of these wind turbines (WT) essentially become "decoupled" from power system. In addition, the inertia of the system becomes time-varying due to the constant change in the power generated by the RES. In emergency modes in systems with less inertia, the rate of change in frequency and other operating parameters is faster [3-7]. The analysis carried out [6] shows that for the period from 1996 to 2016 the overall value of inertia in Europe decreased by $20 \%$. Systems with less inertia can quickly lose their stability in the event of serious accidents, the out-of-step mode in such systems can be mistaken for a short circuit. Thus, large-scale integration of renewable energy sources reduces the inertial properties of EPS and creates problems with ensuring its stability. In this case, the operating systems of emergency control automation, for example, the out-of-step protection (OSP), can be insensitive to rapidly occurring changes in the EPS.

In accordance with this, the purpose of this article is to evaluate the operation of a WPP consisting of a Type 4 WT (with a synchronous generator and excitation from permanent magnets, connected to the EPS through a power voltage converter) for the change in the total inertia of EPS and the rate of the transients.

\section{Assessment of the network total inertia}

In the electric power engineering, it is customary to evaluate inertia by the value of $H$ - the constant inertia of the unit:

$$
H=\frac{E}{S}=\frac{J_{\Sigma} \omega^{2}}{2 S}
$$

where $J_{\Sigma}$ - total unit inertia, $E$ - kinetic energy, $S$ - rated apparent power of the unit. 
The total inertia of the EPS $H_{E P S}$ is calculated according to:

$$
H_{E P S}=\frac{\sum_{i=1}^{n} H_{i} s_{i}}{S_{E P S}},
$$

where $H_{i}$ and $S_{i}$ - constant inertia and rated apparent power of the $i$-th generator, $n$ - total number of synchronous generators connected to the grid, $S_{E P S}$ - full power of the power system, which is equal to the sum of the rated powers of the operating units.

Along with traditional large synchronous generators, wind turbines have a significant amount of kinetic energy of rotating masses:

$$
E=\frac{1}{2} J \omega^{2},
$$

where: $J$ - wind wheel inertia, $\omega$ - the angular speed of the wind wheel.

However, in the case of Type 4 WT, this energy does not affect the total inertia of the EPS, since the mechanical part is separated from the EPS by a power converter. According to (2), the integration of modern WT into the EPS actually increases the total installed capacity of the $S_{E P S}$, but the constant inertia remains the same, which negatively affects the frequency response of the system, since the dynamics of the frequency change in the EPS depends on the total inertia $\mathrm{H}_{E P S}$ [7]:

$$
\frac{2 H_{E P S}}{f_{0}} \frac{d f}{d t}=P_{M \Sigma}-P_{E L \Sigma}=\Delta P_{E P S}
$$

where: $f_{0}$ - set frequency of EPS, $f$ - current EPS frequency, $P_{M \Sigma}, P_{E L \Sigma}-$ full mechanical and electromagnetic power of EPS units, $\Delta P_{E P S}$ - increment of power imbalance of EPS at natural frequency $f$.

The EPS frequency $f$ is inextricably linked with the rotor speed of all synchronous machines of the EPS and is an electromechanical variable that must be constantly and accurately controlled with the help of appropriate automation devices. A change in the active power $\Delta P$ in any region of the EPS contributes to a change in the frequency $\Delta f$.

\section{The EPS model development}

As a platform for operating modes simulating and analyzing the impact of WPP on the EPS stability, an EPS model was developed, the single-line scheme of which shown in Figure 1.

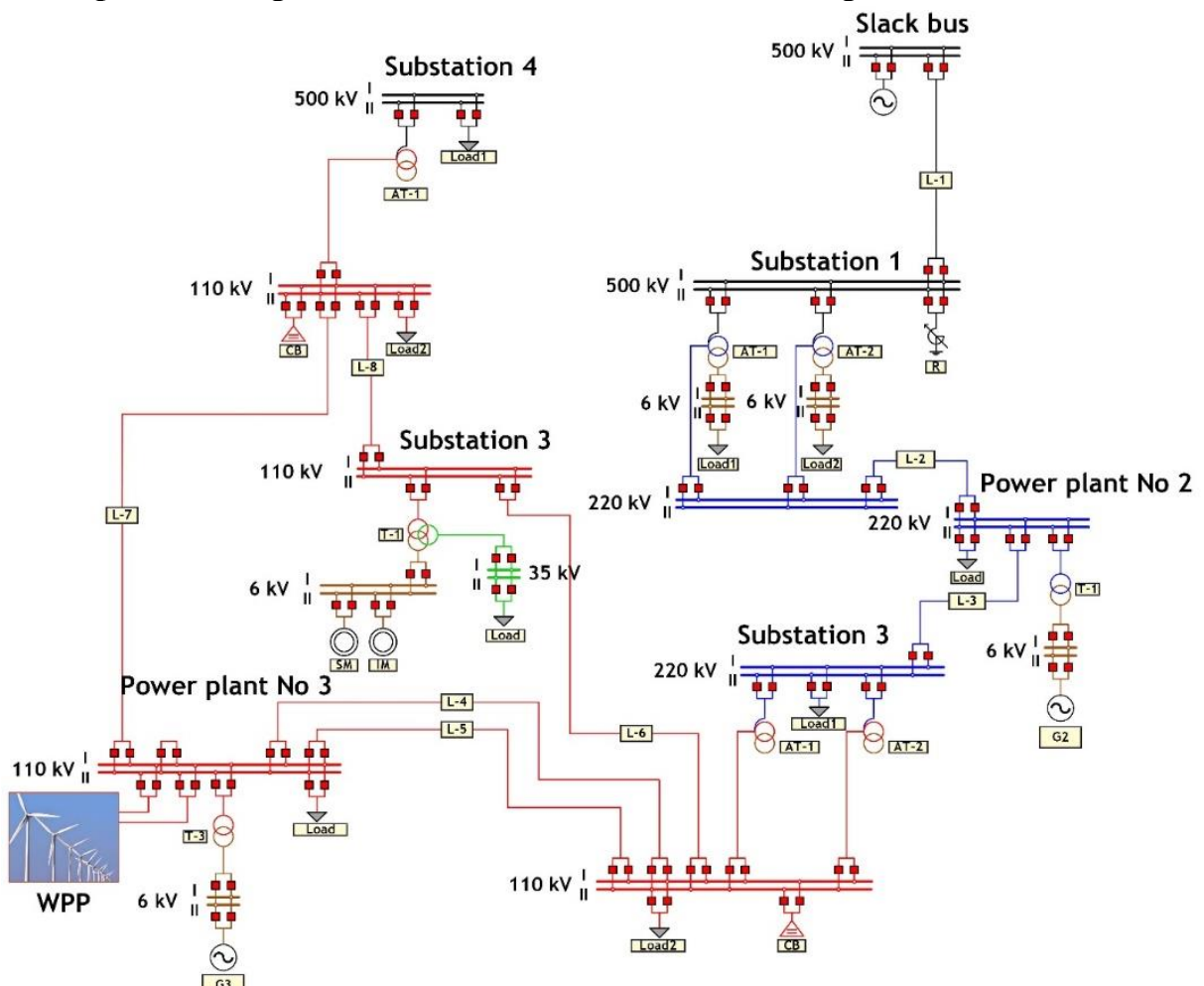

Fig.1. The EPS model 
The EPS model is implemented in the Hybrid Real-Time Power System Simulator (HRTSim). HRTSim is a hybrid-type multiprocessor software-technical system that combines a set of specialized hybrid processors (SP) of all significant equipment of the simulated EPS [8-9]. The EPS model contains: Slack Bus, 500,220 and $110 \mathrm{kV}$ transmission lines, transformers, compensating devices, static and dynamic loads (synchronous and induction motors), a turbine generator G2 of a rated capacity of 225 MVA and G3 of a rated capacity of 180 MVA. The WPP is the equivalent of Type 4 WT, the SP of which was previously developed and fully verified by the authors [10-11].

For the research, the following conditions and assumptions were adopted:

1. The aerodynamic model is reproduced by the expression generally accepted in world practice [12]:

$$
P_{M}=\frac{1}{2} \rho \pi R^{2} V_{W}^{3} C_{P}(Z, \beta) .
$$

2. The wind speed change during the simulation according to [13].

3. The mechanical part of the WT is represented by a two-mass model [14].

4. The model for controlling the pitch angle is based on two PI-controllers: the reference signals are the "errors" of the generator power $\mathrm{P}_{\mathrm{G}}$ and the turbine speed $\omega$, which are compared with the corresponding settings [14].

5. The torque regulator is represented by a PI-regulator, the function of which allows the wind turbine to work at the point of optimal power (MPPT). The controller is implemented according to [15].

6. The voltage source converter control is implemented according to [16].

7. Protection of Type 4 WT and EPS against overvoltage / current and frequency is not applied, since the article examines the effect on the asynchronous mode.

\section{Case study: Assessment of WPP impact on EPS stability}

To assess the impact of WPP operation on the stability of the studied EPS, an emergency situation was simulated: a three-phase fault at time $t=0.2 \mathrm{sec}$ on the L-2 line with its subsequent disconnection, leading to a break in the connection of the EPS with the Slack bus, violation of stability and the emergence of out-ofstep mode. The experiments were carried out while replacing the power of the traditional source G3 with the power generated by the WPP in various ratios, while the total power of the EPS did not change: $\mathrm{P}_{\mathrm{WPP}}=20$ MW (11\% of the G3 power), $\mathrm{P}_{\mathrm{WPP}}=60 \mathrm{MW}$ (33\% of the G3 power), $\mathrm{P}_{\mathrm{WPP}}=100 \mathrm{MW}$ (55\% of G3 power) $\mathrm{P}_{\mathrm{WPP}}=160 \mathrm{MW}$ (90\% of G3 power). According to (1.2), the change in $\mathrm{H}_{\mathrm{EPS}}$ of the total inertia of the EPS when replacing traditional generation has the following values:

Table 1. The EPS total inertia value for WPP integration.

\begin{tabular}{|c|c|c|}
\hline WPP power level, MW & $H_{E P S}$, sec. & $\Delta H$, sec. \\
\hline 0 & 8.745 & - \\
\hline 20 & 8.341 & 0.404 \\
\hline 60 & 7.535 & 1.210 \\
\hline 100 & 6.728 & 2.017 \\
\hline 160 & 5.478 & 3.267 \\
\hline
\end{tabular}

In the investigated emergency state, after disconnecting the L-2 line, the G2 and G3 generators are electrically connected through: line L-3, group AT at Substation 2 and lines L-4 and L-5. Suppose that an OSP device is installed on the L-3 line outgoing from Power Plant No2, which measures the angle between the voltages at the ends of the line, i.e. from the Power Plant No2 and at the end of the controlled area (in our case, at the opposite of the line end) on the $220 \mathrm{kV}$ buses of Substation 2. Figure 2 shows waveforms of the mutual angle between the voltages at the ends of the L-3 line.

In the post-emergency state, at the moment of disconnection of the L-2 line $(\mathrm{t}=0.5 \mathrm{sec})$, an out-of-step mode is observed, the voltage vectors at the ends of the L-3 line turn relative to each other and the controlled angle $\delta$ intersects $\pm 180^{\circ}$. Turning angle $\delta$ in the positive direction corresponds to an increase in frequency and excess power in the part of the EPS connected to the far end of the controlled line. Out-of-step mode also indicates that the electrical swing center is located on the monitored line. 


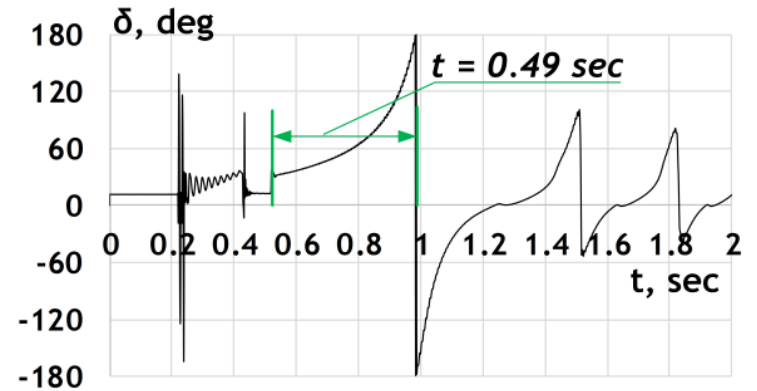

a)

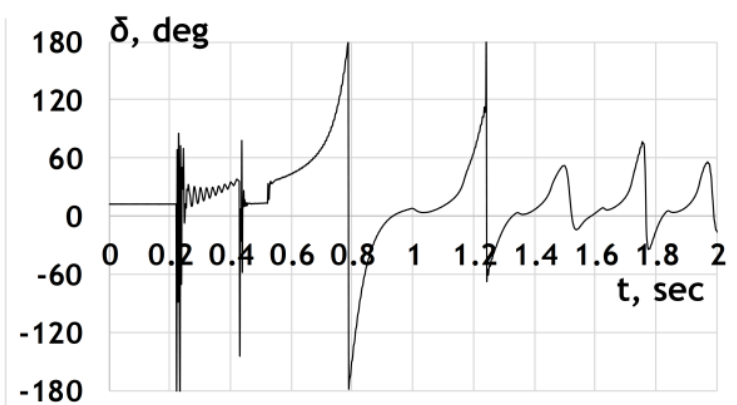

c)

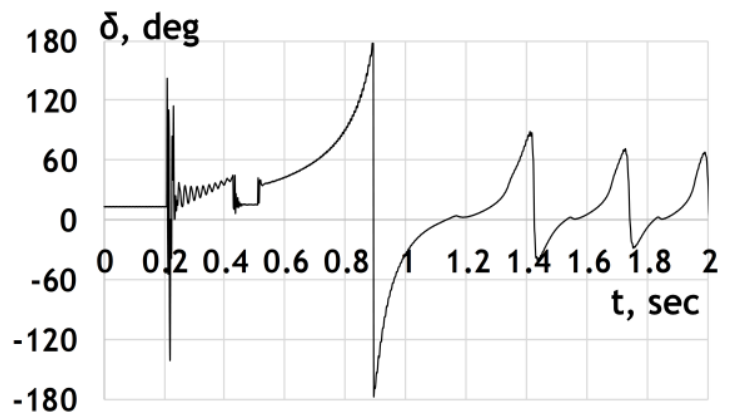

b)

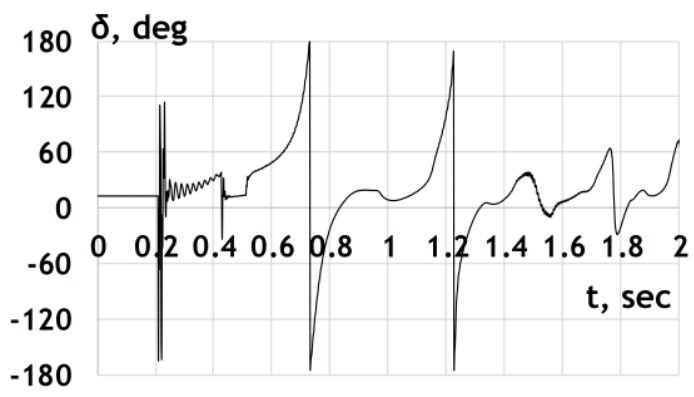

d)

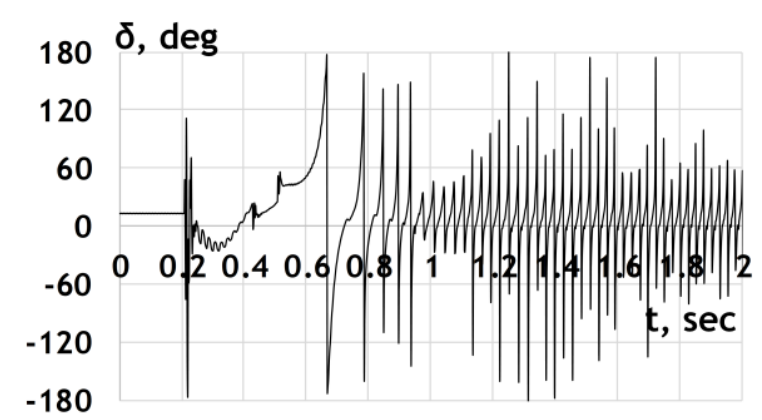

e)

Fig.2. The waveforms of the mutual angle of voltages at the ends of the line L-3

a) without WPP; b) WPP rated power $20 \mathrm{MW}$; c) WPP rated power $60 \mathrm{MW}$; d) WPP rated power $100 \mathrm{MW}$; e) WPP rated power $162 \mathrm{MW}$.

In the process of the development of the out-of-step mode, the rate of increase in the angle difference rapidly increases with the increase in the share of WPP power in the EPS, in particular, from the moment the L-2 line is disconnected. A summary is shown in Table 2. With the development of the out-of-step mode in EPS with traditional generation, the change in the angle $\delta$ occurs more slowly due to the inertia of electromechanical processes, however, the replacement of traditional generators WPP, which reduce the inertia of the EPS, significantly accelerates the process.

Table 2. The time development of EPS out-of-step mode with WPP integration.

\begin{tabular}{|c|c|}
\hline WPP power level, MW & The time of out-of-step mode development, sec. \\
\hline 0 & 0.49 \\
\hline 20 & 0.39 \\
\hline 60 & 0.29 \\
\hline 100 & 0.23 \\
\hline 160 & 0.19 \\
\hline
\end{tabular}


The Figure 3 shows waveforms of the angle $\delta$ (between the EMF) of the generators G2, G3 and the Slack Bus and the relative angle $\delta 23$, which characterizes the operation of G2 and G3 in post-emergency state, when they remain isolated from the Slack Bus.
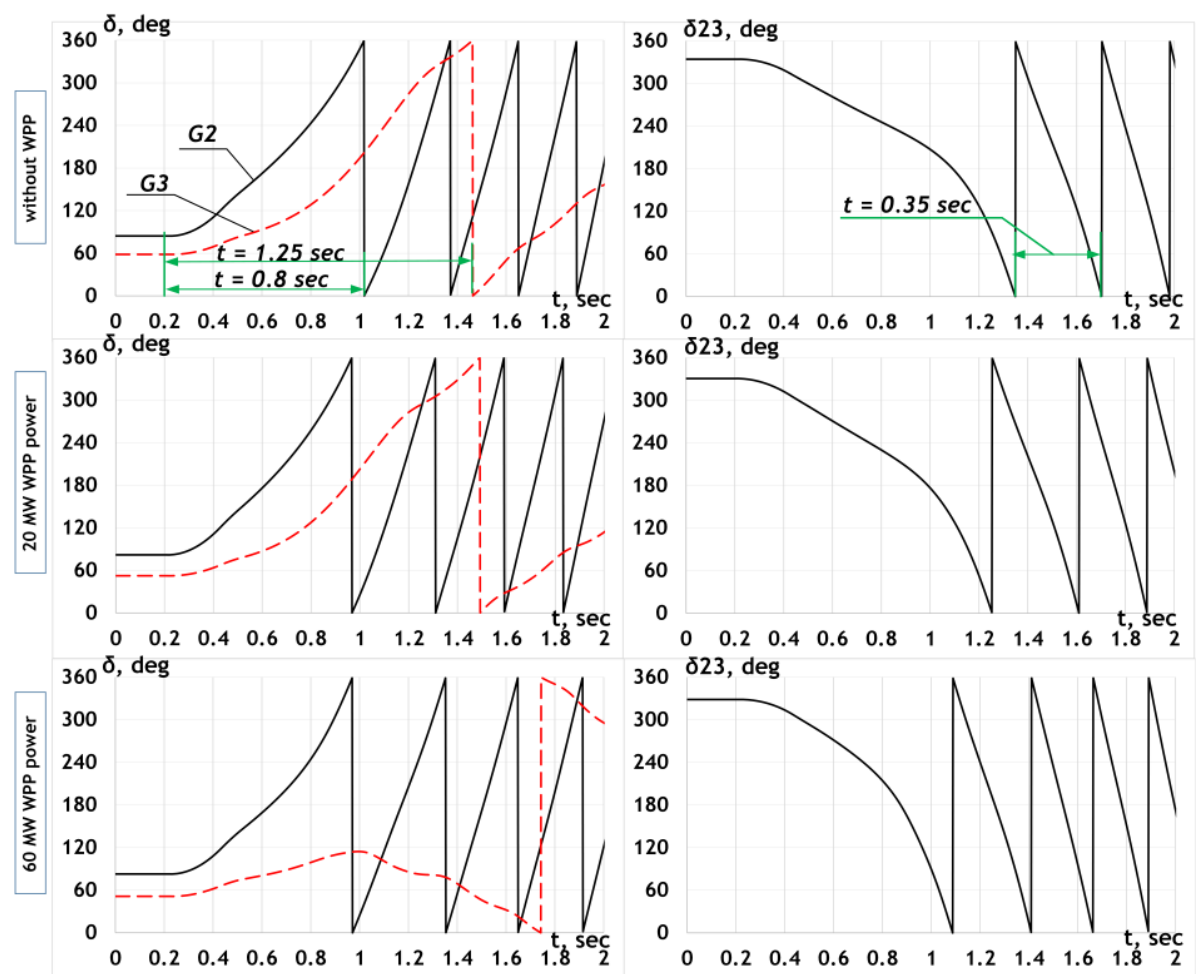

$60 \delta 23$, deg
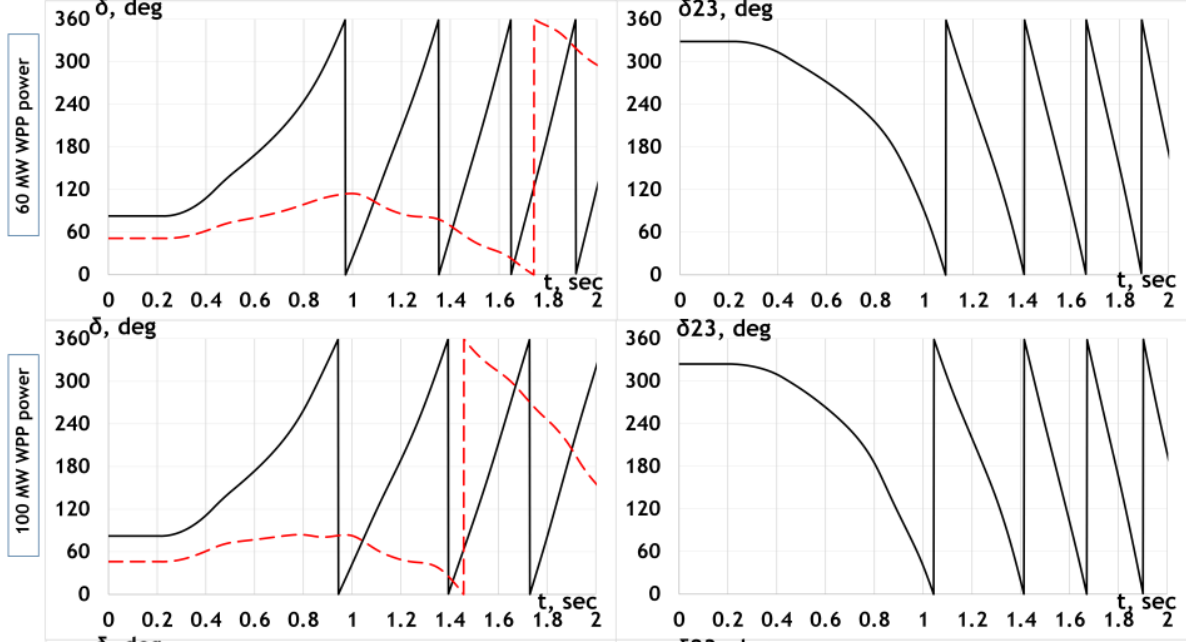

$360 \delta 23, \mathrm{deg}$

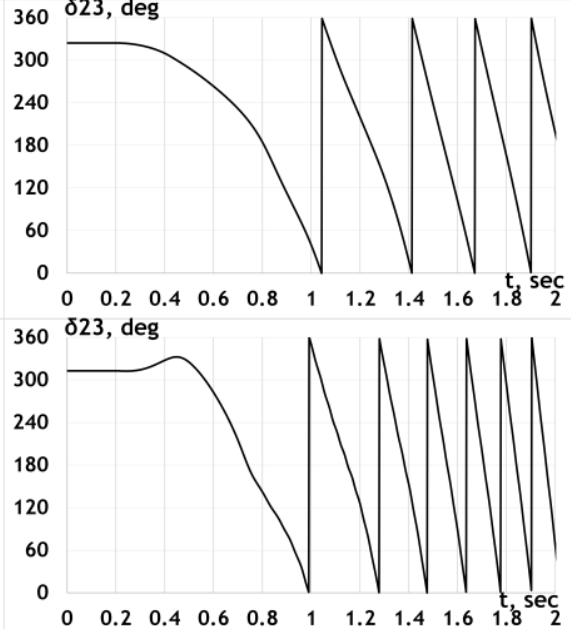

Fig.3. The waveforms of the G2 and G3 $\delta$ angle between slack bus and waveform of $\delta 23$ angle between to each other

At a WPP power of 0 and $20 \mathrm{MW}$, respectively, rotation of the angle $\delta \mathrm{G} 3$ is observed once, i.e. then G3 returns to stable operation. In general, a similar situation is observed when, for example, a change in the angle $\delta \mathrm{G} 3$ in a post-emergency state in EPS with a predominant traditional generation occurs more slowly due to inertia, however, when the power G3 is replaced by the power of WPP, the processes accelerate. In particular, the violation of the synchronous operation of G3 during the integration of the WPP occurs faster, and the relative angle $\delta 23$ also changes faster, which is noticeable from the cycles of asynchronous swings in the EPS. The summary data on the time for which the stable operation of G3 is disrupted and the time of the first cycle of out-of-step mode between G2 and G3 in the post-emergency state are given in Table 3.

Acceleration of processes can lead to improper operation of both the OSP device itself and OSP protection from redundant triggers when the angle $\delta$ of the protected object is changed, which is not related to the development of out-of-step mode, since the main sign of the difference between the out-of-step mode development process and emergency and switching processes is an increase in the operating parameter at the 
current measurement interval by no more than two times in relation to its change at the previous measurement intervals. Experiments show that the acceleration of processes, in particular the development of the out-of-step mode and the change in the mutual angle between the voltages at the ends of the L-3 line, occur quickly enough, which can cause the emergency automation to malfunction.

Table 3. Disturbance of G3 stability and the time of the first cycle of out-of-step mode

\begin{tabular}{|c|c|c|c|}
\hline $\begin{array}{c}\text { WPP power level, } \\
\text { MW }\end{array}$ & $\begin{array}{c}\text { Break through time stable } \\
\text { operation G2, sec. }\end{array}$ & $\begin{array}{c}\text { Break through time stable } \\
\text { operation G3, sec. }\end{array}$ & $\begin{array}{c}\text { Time of the first cycle of out- } \\
\text { of-step mode, sec. }\end{array}$ \\
\hline 0 & 0.80 & 1.25 & 0.35 \\
\hline 20 & 0.78 & 1.32 & 0.35 \\
\hline 60 & 0.78 & 1.52 & 0.31 \\
\hline 100 & 0.78 & 1.29 & 0.36 \\
\hline 160 & 5.478 & 3.267 & 0.28 \\
\hline
\end{tabular}

\section{Conclusions}

Experiments carried out in the article showed that with the integration of WPP, the total inertia in the EPS decreases. Due to the decrease in the total inertia, changes in the out-of-step mode parameters also occur. In particular, with an increase in the power of the WPP, the development time of the out-of-step mode and the time during which traditional generators fall out of synchronism decreases, which confirms the fact that the WPP affects the total inertia in the EPS and the rate of transient processes. In addition, with a sufficiently high share of WPP power in the EPS, equal to 90\% (160 MW), strong fluctuations are observed.

The impact of WPP integration on the change in the total inertia requires the deep analysis. The directions of the further research will be devoted to the study of the influence of the WPP on transient processes and the reduction of the total inertia at various locations of the WPP in the EPS. Studies are also planned aimed at varying the models of WPP and infinite bus models for transient processes in EPS in various operating modes.

\section{Acknowledgements \\ The work was supported by Ministry of Science and Higher Education of Russian Federation, according to the research project No. MK-3249.2021.4.}

\section{REFERENCES}

1 Renewables 2020 Global Status Report. Available at: https://www.ren21.net/reports/global-status-report/

2 GWEC. Global Wind Statistics 2019. Global Wind Energy Council, Brussels, Belgium, Tech. Rep. (2020). Available: https://gwec.net/global-wind-report-2019/

3 Tielens P., Hertem D. V. The relevance of inertia in power systems. Renewable Sustain. Energy Rev. 2016, Vol. 55, pp. 999-1009, doi:10.1016/j.rser.2015.11.016.

4 Erlich I., Wilch M. Primary frequency control by wind turbines. Proceedings of the "2010 IEEE power and energy society general meeting”, Minneapolis, USA. 2010, pp. 1-8.

5 Gautam D., Goel L., Ayyanar R., Vittal V., Harbour T. Control strategy to mitigate the impact of reduced inertia due to doubly fed induction generators on large power systems. IEEE Transactions on Power Systems. 2011, Vol. 26, No. 1, pp. 214-224, doi: 10.1109/TPWRS.2010.2051690.

6 Fernandez-Guillamon A. et al. Power systems with high renewable energy sources: A review of inertia and frequency control strategies over time. Renewable and Sustainable Energy Reviews, 2019, Vol. 115, pp. 109369. doi: 10.1016/j.rser.2019.109369

7 Gonzalez-Longatt, F. Impact of emulated inertia from wind power on under-frequency protection schemes of future power systems. Journal of Modern Power Systems and Clean Energy, 2016, pp. 1 - 8. doi:10.1007/s40565-0150143-x.

8 Razzhivin, I., Askarov, A., Rudnik, V. and Suvorov, A. A Hybrid Simulation of Converter-Interfaced Generation as the Part of a Large-Scale Power System Model, International Journal of Engineering and Technology Innovation, 2021, 11(4), pp. 278-293. doi: 10.46604/ijeti.2021.7276. 
9 Suvorov A., Gusev A., Ruban N., et al. Potential Application of HRTSim for Comprehensive Simulation of Large-Scale Power Systems with Distributed Generation. International Journal of Emerging Electric Power Systems. 2019, Vol. 20, No. 5, pp. 20190075.

10 Ufa R., Andreev M., Ruban N., et al. The hybrid model of VSC HVDC. Electrical Engineering. 2019, Vol.101, No. 1, pp. 11 - 18. doi: 10.1007/s00202-018-00752-y.

11 Andreev M., Ruban N., Suvorov A., et al. A Hybrid Model of Type-4 Wind Turbine - Concept and Implementation for Power System Simulation. Proceedings of the "2020 IEEE PES Innovative Smart Grid Technologies Europe (ISGT-Europe)”. 2020, pp.799 - 803. doi: 10.1109/ISGT-Europe47291.2020.9248860

12 Price W.W., Sanchez-Gasca J.J. Simplified Wind Turbine Generator Aerodynamic Models for Transient Stability Studies. Proceedings of the "IEEE PES Power Systems Conference and Exposition". 2006, pp. 986-992. doi: 10.1109/PSCE.2006.296446.

13 Obukhov S.G., Plotnikov I.A., Masolov V.G. Dynamic wind speed model for solving wind power problems Eurasian phys. tech. j. 2020, Vol.17, No.33, pp.77-84.

14 Clark, N. W. Miller, and J. J. Sanchez-Gasca, Modeling of GE wind turbine-generators for grid studies $G E$ energy, vol. 4, pp. 0885-8950,2010

15 Wu B., Lang Y., Zargari N., Kouro S. Power Conversion and Control of Wind Energy Systems. 2011, 480 p.

16 Yaramasu V., Dekka A., Duran M.J., Kouro S., Wu B. PMSG-based wind energy conversion systems: Survey on power converters and controls. IET Electr. Power Appl. 2017, Vol. 11, pp. 956-968. doi:10.1049/ietepa.2016.0799. 